\title{
Climate-based risk models for Fasciola hepatica in Colombia
}

\author{
Natalia Valencia-López ${ }^{1}$ John B. Malone², Catalina Gómez Carmona ${ }^{1}$,Luz E. Velásquez ${ }^{3}$ \\ ${ }^{1}$ Programa de Estudio y Control de Enfermedades Tropicales-PECET, Sede de Investigación Universitaria-SIU, \\ Torre II, Laboratorio 730, Medellin, Colombia; ${ }^{2}$ Department of Pathobiological Sciences, School of Veterinary \\ Medicine, Louisiana State University, Baton Rouge, LA 70803, USA; ${ }^{3}$ Grupo Microbiología Ambiental. Escuela \\ de Microbiología. Universidad de Antioquia
}

\begin{abstract}
A predictive Fasciola hepatica model, based on the growing degree day-water budget (GDD-WB) concept and the known biological requirements of the parasite, was developed within a geographical information system (GIS) in Colombia. Climate-based forecast index (CFI) values were calculated and represented in a national-scale, climate grid $(18 \mathrm{x} 18 \mathrm{~km})$ using ArcGIS 9.3. A mask overlay was used to exclude unsuitable areas where mean annual temperature exceeded $25{ }^{\circ} \mathrm{C}$, the upper threshold for development and propagation of the F. hepatica life cycle. The model was then validated and further developed by studies limited to one department in northwest Colombia. F. hepatica prevalence data was obtained from a 2008-2010 survey in 10 municipalities of 6,016 dairy cattle at 673 herd study sites, for which global positioning system coordinates were recorded. The CFI map results were compared to F. hepatica environmental risk models for the survey data points that had over $5 \%$ prevalence (231 of the 673 sites) at the $1 \mathrm{~km}^{2}$ scale using two independent approaches: (i) a GIS map query based on satellite data parameters including elevation, enhanced vegetation index and land surface temperature day-night difference; and (ii) an ecological niche model (MaxEnt), for which geographic point coordinates of F. hepatica survey farms were used with BioClim data as environmental variables to develop a probability map. The predicted risk pattern of both approaches was similar to that seen in the forecast index grid. The temporal risk, evaluated by the monthly CFIs and a daily GDD-WB forecast software for 2007 and 2008, revealed a major July-August to January transmission period with considerable inter-annual differences.
\end{abstract}

Keywords: Fasciola hepatica, Colombia, climate forecast, geographical information systems, maximum entropy, ecologic niche modelling.

\section{Introduction}

Fasciola hepatica is an important cause of losses in animal productivity in sheep and cattle in Colombia, and F. hepatica is known to be an important zoonotic infection of humans in the Andean region (Marín and Martínez, 1977; Griffiths, 1986; Olaechea, 1994; Fuentes et al., 1999; Mas-Coma et al., 2001, 2005). An incomplete understanding of the epidemiology of this snail-borne disease in Colombia currently limits design of appropriate control programmes based on identification of high-risk areas, seasonal transmission, economic losses in livestock and potential public health impact.

The distribution and abundance of $F$. hepatica is highly related to certain known environmental conditions (Olaechea, 1994; Dutra et al., 2010) and conforms to the "natural nidality of disease" concept and

\footnotetext{
Corresponding author:

Natalia-Valencia-López

Programa de Estudio y Control de Enfermedades Tropicales-PECET Sede de Investigación Universitaria-SIU Torre II, Laboratorio 730 Calle 62 No 52-59, Medellín, Colombia

Tel. +57 4219 6514; Fax +57 42196511

E-mail: nataval15@gmail.com
}

landscape epidemiology. Introduced by Pavlovsky in 1966, the concept of natural nidality describes the unique relationship between a vector-borne disease and its host(s), which together form an ecosystem in a geophysical location in the landscape (biocoenose) Climatic factors in particular have been reported to be a sensitive means of forecasting annual $F$. hepatica prevalence and geospatial variability (Ollerenshaw and Rowlands, 1959; Malone et al., 1987; Fuentes et al., 1999; Malone and Yilma, 1999; Fuentes, 2006).

The climate in this part of the world is strongly influenced by the roughly five years of periodic temperature variations of the surface of the tropical, eastern Pacific Ocean called the El Niño/La Niña Southern Oscillation (ENSO) events. The warm phase is known as El Niño and the cold La Niña and the accepted definition is a warming or cooling of the sea surface temperatures of at least $0.5^{\circ} \mathrm{C}$ compared with the average value. When the warming or cooling occurs for less than a year the period is classified as an ENSO condition and when longer, an ENSO episode (http://iri.columbia.edu/climate/ENSO/background/pa stevent.html).

Geographical information systems (GIS) methodology provides a tool for mapping and modelling risk of 
F. hepatica and other diseases with strong environmental determinants, allowing computer-based analysis of multiple layers of mapped data in digital form, including sensor data from Earth observation satellites, climate data, elevation, vector distribution and disease prevalence (Yilma and Malone, 1998; Malone and Yilma, 1999; Malone, 2005; Dutra et al., 2010). Consistent with the natural nidality concept, we used GIS methodology to develop climate forecast indices and to map endemic areas of fascioliasis in Colombia using models successfully applied elsewhere based on the growing degree day-water budget (GDD-WB) index (Malone et al., 1987; Fuentes et al., 1999; Malone, 2005). This index considers known biologybased suitability parameters of this species from the literature and the two most important factors that influence the establishment and development of the host-parasite system are moisture and temperature (Malone et al., 1987; Olaechea, 1994).

In the present study, we developed and contrasted the results of two fundamental approaches to mapping and modelling the distribution and abundance of fascioliasis in Colombia based on climate - regional scale "biology-based" models and local scale "geostatistical" models. The biology-based climate forecast model (18 x $18 \mathrm{~km}$ grid) was developed covering the entire country based on known biological and climatic requirements of the $F$. hepatica life cycle and GDDWB analysis. The regional GDD-WB forecast grid (18 $\mathrm{x} 18 \mathrm{~km}$ ) was then clipped to the boundaries of Antioquia, a department in northwest Colombia, and used to validate the results and contrast them to two geostatistical modelling methods covering the same area at $1 \mathrm{~km}^{2}$ spatial resolution, first a GIS map query extrapolation and, second an ecological niche model based on maximum entropy software (MaxEnt). The latter is a geostatistical software tool that can be used for building models of a species' geographic distribution based on "presence-only" data points and a list of variables of potential environmental determinants as input. The model predicts probability of the species occurring in areas where no data is available based on modelling significantly associated environmental variables (Phillips et al., 2006).

\section{Materials and methods}

\section{Parasitological data}

F. hepatica prevalence data in cattle was determined in field studies conducted from 2008 to 2010 in three sub-regions of the department of Antioquia in northwestern Colombia. A total of 10 municipalities were selected for study (Table 1; Fig. 1) based on their importance in the Antioquia dairy industry. The population sample for fascioliasis prevalence data consisted mainly of Holstein-Friesian cattle, but also included other dairy breeds. The total sample consisted of 10 municipalities, 226 veredas (sub-municipality political zones), 673 farms and 6,016 cattle (Table 2).

Global positioning system (GPS) coordinates were recorded for each farm location. Elevation data were extracted from the Shuttle Radar Topography Mission (SRTM) data set (http://www2.jpl.nasa.gov/srtm/) and given as meters above the mean sea level (MSL).

The sedimentation method of Dennis et al. (1954), modified by the Programa de Estudio y Control de Enfermedades Tropicales (PECET) laboratory, was

Table 1. Area, mean temperature and average altitude of 673 farms surveyed in 10 municipalities in Antioquia, Colombia between 2008 and 2010.

\begin{tabular}{llccc}
\hline Subregion & Municipality & Area $\left(\mathrm{km}^{2}\right)$ & Mean temperature $\left({ }^{\circ} \mathrm{C}\right)$ & Average altitude* \\
\hline \multirow{5}{*}{ Northern } & San Pedro de los Milagros & 229 & 16 & 2,534 \\
& Entrerríos & 219 & 16 & 2,455 \\
& Donmatías & 181 & 16 & 2,217 \\
& San José de la Montaña & 123 & 13 & 2,421 \\
& Santa Rosa de Osos & 805 & 13 & 2,540 \\
Solmira & 296 & 14 & 1,603 \\
\hline \multirow{3}{*}{ Easthwestern } & Jardín & 224 & 19 & 1,944 \\
& Jericó & 193 & 18 & 2,239 \\
\hline
\end{tabular}

Source: http://www.antioquia.gov.co/ *Calculated as the average altitude in the sampled farms and expressed as $\mathrm{m}$ above sea level. 


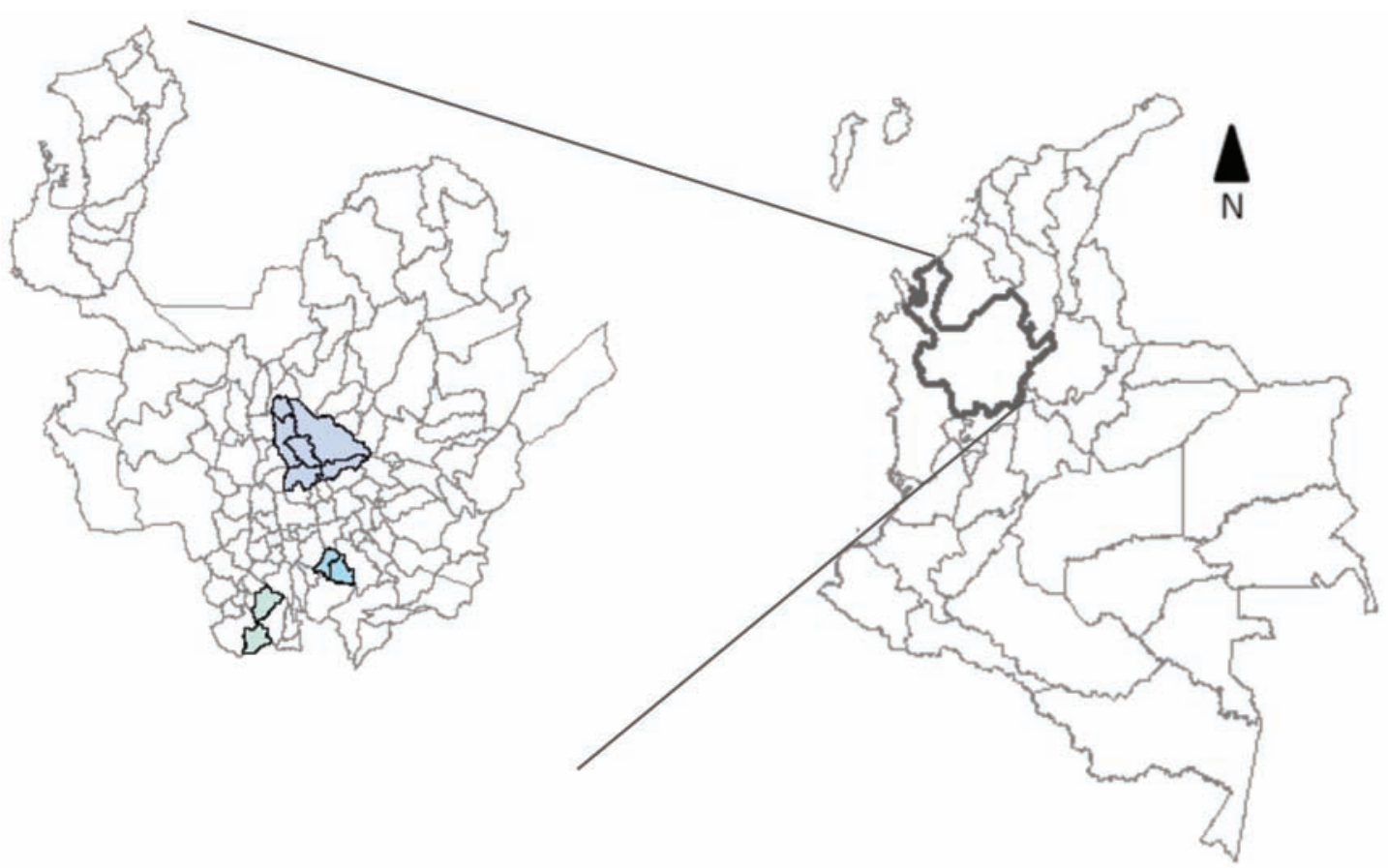

Fig. 1. Map of Colombia (right) and Antioquia (left), showing the 10 municipality survey area.

used to count $F$. hepatica eggs per gram (EPG) of faeces on a statistically valid number of fecal samples from each herd. The number of samples collected from each herd depended on the number of animals in that herd. Herd samples varied from 1 (for small herds) to 92 (for large herds) with an average of 10 faecal samples per herd. Only farms found to present over $5 \%$ prevalence of infection $(\mathrm{n}=231)$ were included in the study.

\section{Climate-based forecast using monthly data}

Moisture and temperature, factors which directly influence the prevalence and transmission of fascioliasis (Olaechea, 1994), were used to calculate a monthly climate forecast index (CFI) for Colombia. This index is based on the GDD-WB concept, and was calculated following the method of Malone et al. (1987) as:

Index $1=G D D x$ Days in month, if R-PET $x 0.8>0$

where $R$ is rainfall and PET potential evapotranspiration (calculated by the Penman method).

The GDD concept assumes that the growth rate of an organism increases within a temperature range. Below the base temperature, the organism does not grow and above the optimum temperature, the growth rate declines (Ruselle et al., 1984). In this formula,

Table 2. Veredas, farms and cattle sampled for each of 10 municipalities in Antioquia.

\begin{tabular}{lcccc}
\hline Municipality & Veredas & Farms & Bovines & F. hepatica prevalence $(\%)$ \\
\hline San Pedro-Milagros & 28 & 52 & 437 & 25.9 \\
Entrerríos & 13 & 63 & 617 & 14.9 \\
Donmatías & 19 & 67 & 545 & 29.0 \\
San José-Montaña & 14 & 70 & 593 & 0.3 \\
Santa Rosa de Osos & 51 & 157 & 1,158 & 7.3 \\
Belmira & 20 & 59 & 572 & 17.0 \\
Jardín & 16 & 52 & 576 & 42.4 \\
Jericó & 22 & 31 & 286 & 1.4 \\
La Ceja & 18 & 47 & 497 & 51.3 \\
La Unión & 25 & 75 & 735 & 26.1 \\
Total & 226 & 673 & 6016 & Mean 21.6 \\
\hline
\end{tabular}


subtracting the factor PETX 0.8 from rainfall is equivalent to adding monthly GDD if moisture storage is present in the top $2.5 \mathrm{~cm}$ layer of a $15 \mathrm{~cm}$ soil depth WB model (Malone and Yilma, 1999). The monthly data and derived forecast calculations were extracted from a climate grid $(18 \times 18 \mathrm{~km})$ of South America (30year-average data) using the point-polygon extraction function of ArcGIS 9.3 (ESRI, Redlands, CA, USA). The climate grid was kindly provided by John Corbett, Mudsprings Geographers, Temple, Texas, USA.

The monthly mean temperature $(\mathrm{MnT})$ was calculated using minimum temperature (IT) and maximum temperature (XT) (eq. 2) in order to calculate GDD, using the GDD base temperature of $10{ }^{\circ} \mathrm{C}$ (eq. 3). Since the thermal tolerance limit for the establishment of the parasite-snail system ranges from $10{ }^{\circ} \mathrm{C}$ to 25 ${ }^{\circ} \mathrm{C}$ (Olaechea, 1994; Fuentes and Malone, 1999; Fuentes et al., 1999; Dutra et al., 2010), the MnT values that were not within this range were assumed as null values.

$$
\begin{gathered}
M n T=I T-X T 2 \\
G D D=M n T-10{ }^{\circ} \mathrm{C} x \text { days of month (eq. 3) }
\end{gathered}
$$

Climate-based daily forecast and seasonal transmission in Antioquia

In order to evaluate the temporal risk and interannual variation of fascioliasis within Antioquia, Index 1 was calculated, using daily maximum and minimum temperature and rainfall data from a meteorological station located in Cucurucho, Santa Rosa de Osos municipality in the northern sub-region of Antioquia $\left(6^{\circ} 39^{\prime}\right.$ North and $75^{\circ} 30^{\prime}$ West, IDEAM code number 2701523, elevation 2,580 m above sea level. The Climate Based Parasitology Forecast software programme was used for the analysis (Malone et al., 1987). For Antioquia, Index 1 was calculated for each month and annually, considering two time periods: March 2007-February 2008 (Table 3) and March 2008-February 2009 (Table 4).

\section{MaxEnt ecological niche modeling using Bioclim data}

MaxEnt was used to develop a geostatistical probability surface for fascioliasis in Antioquia based on 19 Bioclim variables derived from the WorldClim Organization web site data set, a global 50-year longterm-normal climate data record (http://www.worldclim.org/current). The 3.3.3 version of MaxEnt (www.cs.princeton.edu/ schapire/maxent/) public domain software was downloaded and used in model development (Phillips et al., 2006). Of the 19 Bioclim variables, nine were selected for further study (Table 3) based on an initial MaxEnt model run which indicated that these variables were the most strongly related to the presence of $F$. hepatica.

Table 3. BioClim variables used to develop the MaxEnt model.

\begin{tabular}{lc}
\hline Variable description & Abbreviation \\
\hline Annual mean temperature & $\mathrm{BIO} 1$ \\
Mean diurnal range (Mean of monthly (max-min temp)) & $\mathrm{BIO} 2$ \\
Isothermality & $\mathrm{BIO3}$ \\
Temperature seasonality & $\mathrm{BIO} 4$ \\
Temperature annual range & $\mathrm{BIO} 7$ \\
Mean temperature of wettest quarter & $\mathrm{BIO} 8$ \\
Annual precipitation & $\mathrm{BIO} 12$ \\
Precipitation seasonality & $\mathrm{BIO} 15$ \\
Precipitation of the wettest quarter & $\mathrm{BIO} 16$ \\
\hline
\end{tabular}

\begin{tabular}{|c|c|c|c|c|}
\hline Month & Index 1 & Precipitation (mm) & Water surplus (mm) & GDD \\
\hline March & 0 & 33.3 & 1.0 & 124 \\
\hline April & 0 & 13.2 & 0.4 & 94 \\
\hline May & 0 & 57.1 & 2.0 & 94 \\
\hline June & 51 & 208.5 & 19.0 & 124 \\
\hline July & 1085 & 406.1 & 247.7 & 124 \\
\hline August & 337 & 163.6 & 54.2 & 124 \\
\hline Sep & 211 & 149.1 & 35.6 & 124 \\
\hline Oct & 534 & 260.1 & 146.5 & 95 \\
\hline Nov & 347 & 198.9 & 84.8 & 93 \\
\hline Dec & 704 & 306.5 & 203.2 & 93 \\
\hline Jan & 409 & 193.3 & 105.4 & 93 \\
\hline Feb & 27 & 77.8 & 4.0 & 93 \\
\hline Total & 3705 & 2067.5 & 903.8 & 1182 \\
\hline
\end{tabular}

Table 4. Monthly Index1, water budget and GDD values, March 2007-February 2008. 


\section{GIS query-MODIS model}

The spatial analyst extension of ArcGIS 9.3 was used to create $1 \mathrm{~km}$ radius buffer zones centered on herd prevalence data points and to extract data on elevation (SRTM) and MODIS data (http://modis.gsfc.nasa.gov/) with respect to the enhanced vegetation index (EVI) and the day and night land surface temperature (LST). Additionally, a subtraction of $\mathrm{LST}_{\text {night }}$ from $\mathrm{LST}_{\text {day }}$ images provided day-night temperature difference $(\mathrm{dT})$ values in the buffer extraction data as an indicator of soil moisture regime. The data from the buffer extractions were analyzed to identify the range of values of these variables that are related to the presence of F. hepatica at the 231 sites with $>5 \%$ prevalence. These "suitable" value ranges were then used to run map queries that allowed differentiation of the suitable areas from the unsuitable areas in Antioquia.

\section{Results}

\section{Climate forecast grid model for Colombia}

Climate grid cell values $(18 \times 18 \mathrm{~km})$ were used to build a risk map for fascioliasis in Colombia (Fig. 2), with darker colors indicating riskier areas. Much of the country fell into areas with average annual temperatures above $25^{\circ} \mathrm{C}$, a condition reported to restrict the development of the lymnaeid snail-F. hepatica system (Malone and Yilma, 1999). A GIS “mask" overlay of grid cells with average annual temperatures $>25^{\circ} \mathrm{C}$ was therefore created to exclude unsuitable areas above this threshold, resulting in a map showing only the areas suitable for development and propagation of $F$. hepatica. Such areas were found mainly in the high elevation Andean zone (Fig. 3). Fig. 4 shows the boundaries of Antioquia on an SRTM topographical map of Colombia.

\section{Temporal pattern}

Tables 4 and 5 show results for Antioquia of monthly precipitation (PRE), water surplus, GDD (sum of the mean monthly temperatures $>10^{\circ} \mathrm{C} \mathrm{x}$ days in each month) and monthly values calculated for the climate forecast Index1. Climate data for March 2007February 2009 were obtained from the Cucurucho meteorological station which was considered representative of the area of endemic fascioliasis in Antioquia. The data suggest surplus water conditions suitable for lymnaeid snail habitats and propagation of $F$. hepatica

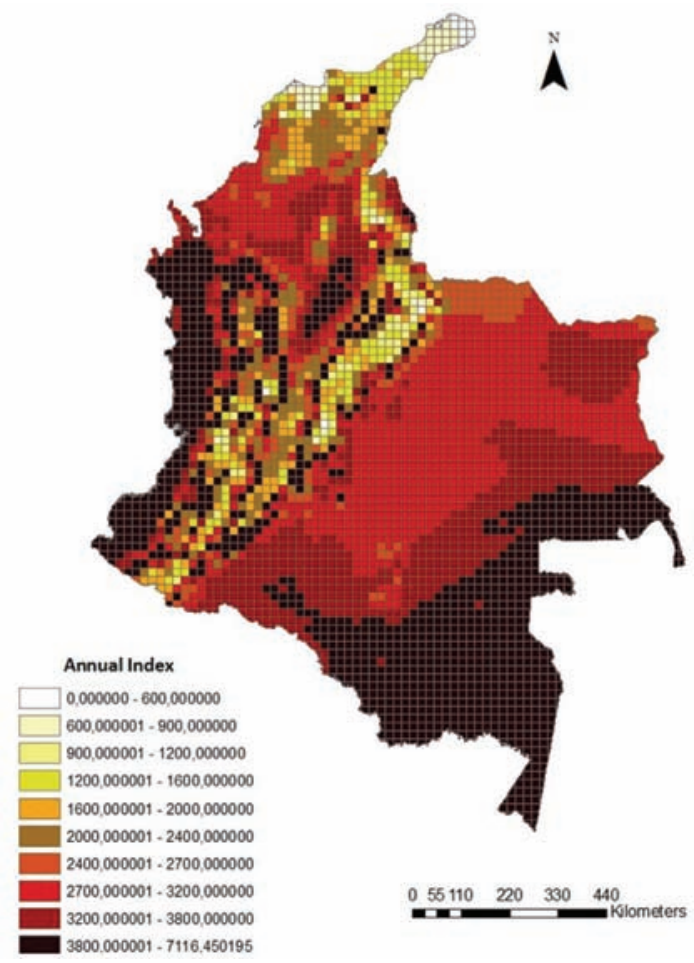

Fig. 2. Spatial distribution of an annual forecast for F. hepatica using climate model Index 1 in Colombia without consideration of the $>25^{\circ} \mathrm{C}$ threshold limiting factor (Malone and Yilma, 1999).

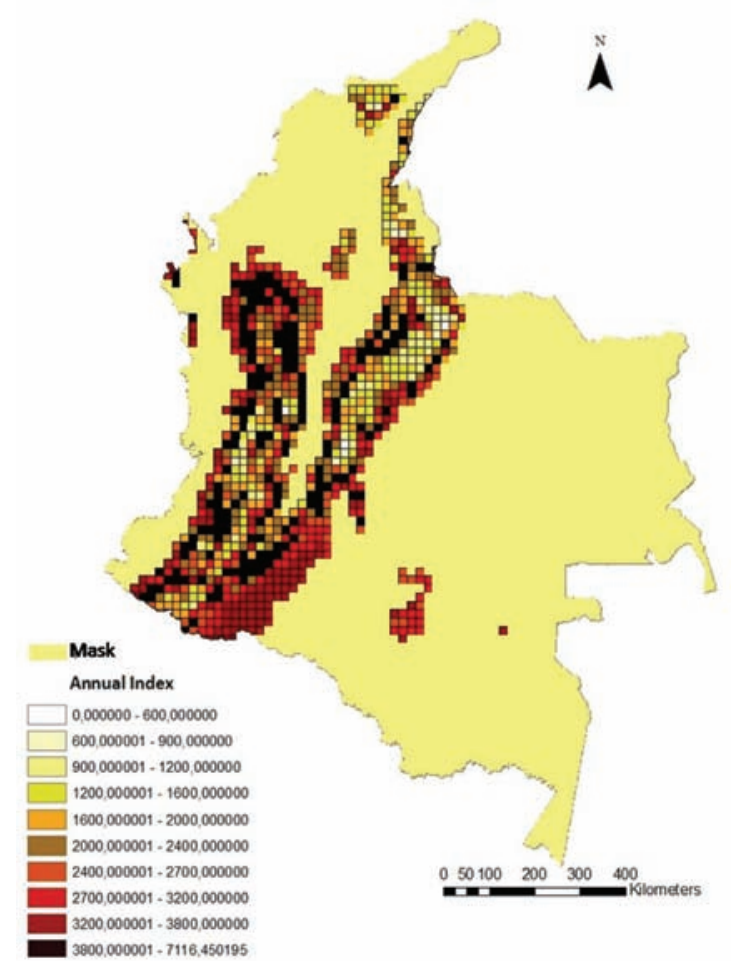

Fig. 3. Risk map of suitable areas for fascioliasis in Colombia, based on the annual Index1. The mask excludes grid cells with average annual temperatures of $>25{ }^{\circ} \mathrm{C}$ as unsuitable for the development and propagation of the $F$. hepatica life cycle. 


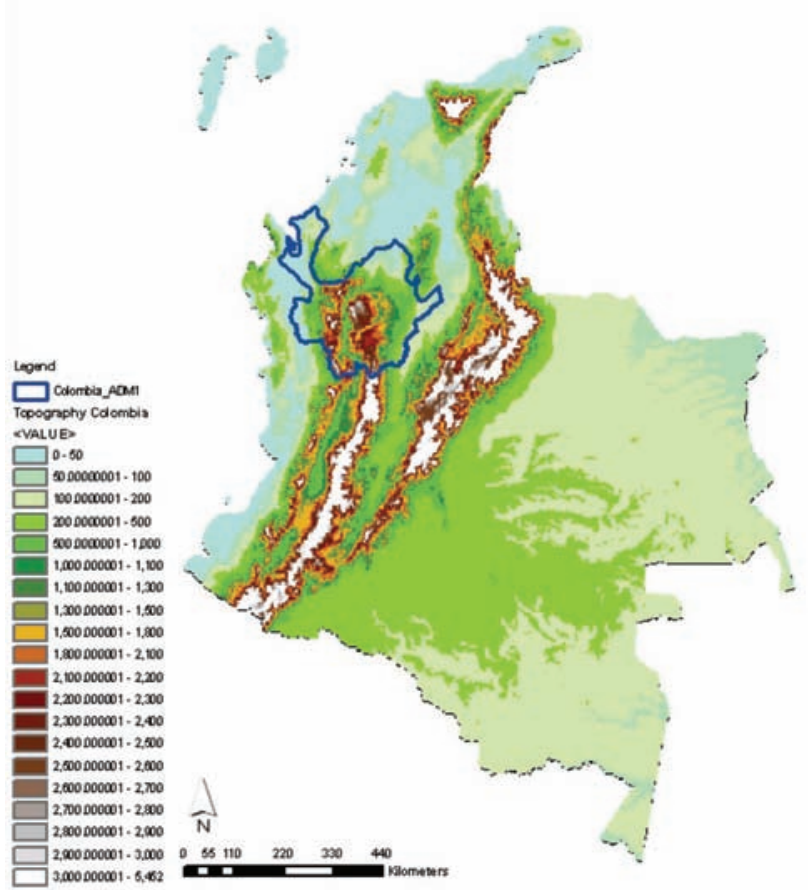

Fig. 4. Topographic map from the Shuttle Radar Topography Mission (SRTM) showing the high-elevation areas of Antioquia in the Andes region. The average altitude of all farms surveyed in each of 10 municipalities ranged from 1,859-2,603 m above sea level.

intramolluscan stages occurred from July to February in 2007-2008 and from August to February in 20082009.

The monthly pattern is shown more clearly in Fig. 5, which is a graphic representation of more detailed forecast output results obtained by using daily climate values and the Climate Based Parasite Forecast System software which incorporates values derived from the GDD-WB concept. The bar diagram at the bottom panel indicates surplus water likely to fill surface water habitats suitable for snail-parasite population activity. This is reflected in the annual soil moisture storage pattern for the upper $25 \mathrm{~mm}$ (blue line) and lower $125 \mathrm{~mm}$ (red line); sustained presence of water in the top $50 \mathrm{~mm}$ was considered to be the beginning of suitable seasonal conditions for development and propagation of the snail-parasite system in Louisiana (Malone et al., 1987). The daily accumulation of forecast index (yellow line) is based on accumulation of two values: (i) the arithmetic sum of GDD, conditional on soil water storage in the top $50 \mathrm{~mm}$ of soil and (ii) accumulation of the product of GDD and surplus water (to reflect the importance of rain events in metacercariae dispersal). The beginning and end of suitable conditions for development and transmission of $F$. hepatica in each year is illustrated by soil moisture storage in the lower $125 \mathrm{~mm}$ level (red line). Total annual Index1 values indicate that 2007-2008 was a more favourable year for F. hepatica than 2008-2009 (Index 13,705 vs 2,684, respectively) and that suitable conditions occurred one month earlier in 2007-2008.

Validation of the climate prediction model in Antioquia by GIS query and MaxEnt modelling

\section{GIS query-MODIS model}

Fascioliasis prevalence in the 10 sampled municipalities in Antioquia varied from $0.3 \%$ to $51.3 \%$ (Table $2)$. The mean prevalence was $21.6 \%(\mathrm{SD}=16.8)$. Assuming that low prevalence values may be due to recently acquired animals, only those herds with prevalence values above $5 \%$ were considered endemic; therefore, the farms that were sampled in Jericó and in San José de la Montaña were excluded.

GIS buffer extraction data from a $1 \mathrm{~km}$ radius area centered on farm point locations were used to identify the critical range of MODIS environmental variables, elevation and temperature difference (dT) relevant to suitability for the lymnaeid snail-F. hepatica system for both 2008 and 2009 (Table 6 ). These "suitable" crit-
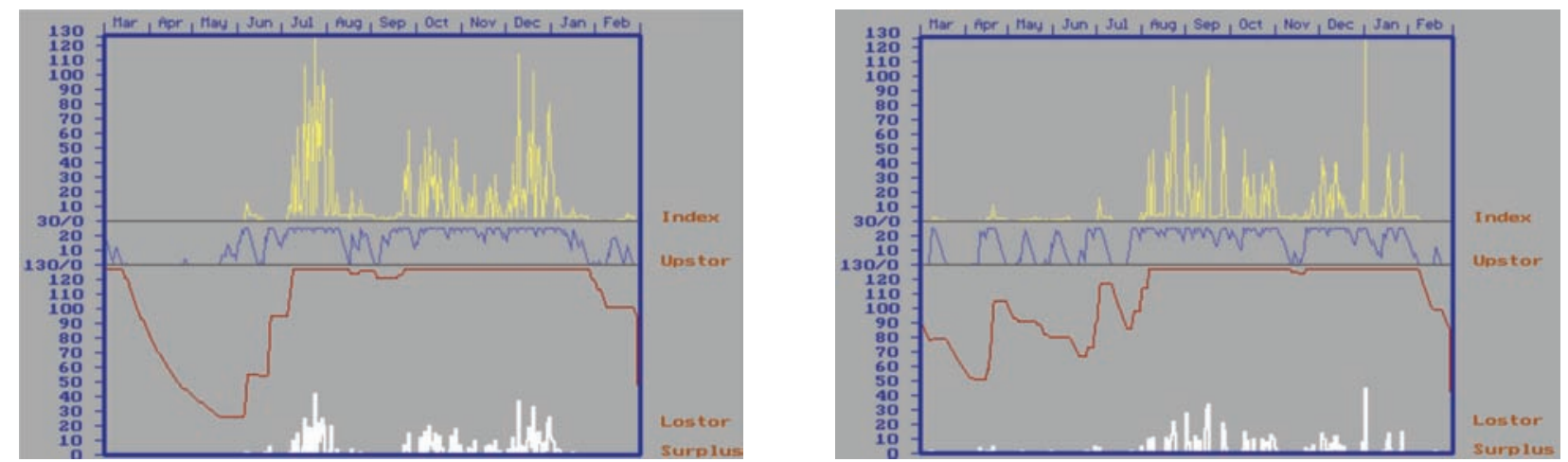

Fig. 5. Graphical representation of daily forecast value calculations by the Climate Based Parasite Forecast System programme. Top: March 2007-February 2008, bottom: March 2008-February 2009. Surplus water = white bars; soil moisture storage, lower $125 \mathrm{~mm}$ = red line; soil moisture storage, upper $25 \mathrm{~mm}=$ blue line; daily accumulation of index = yellow line. 

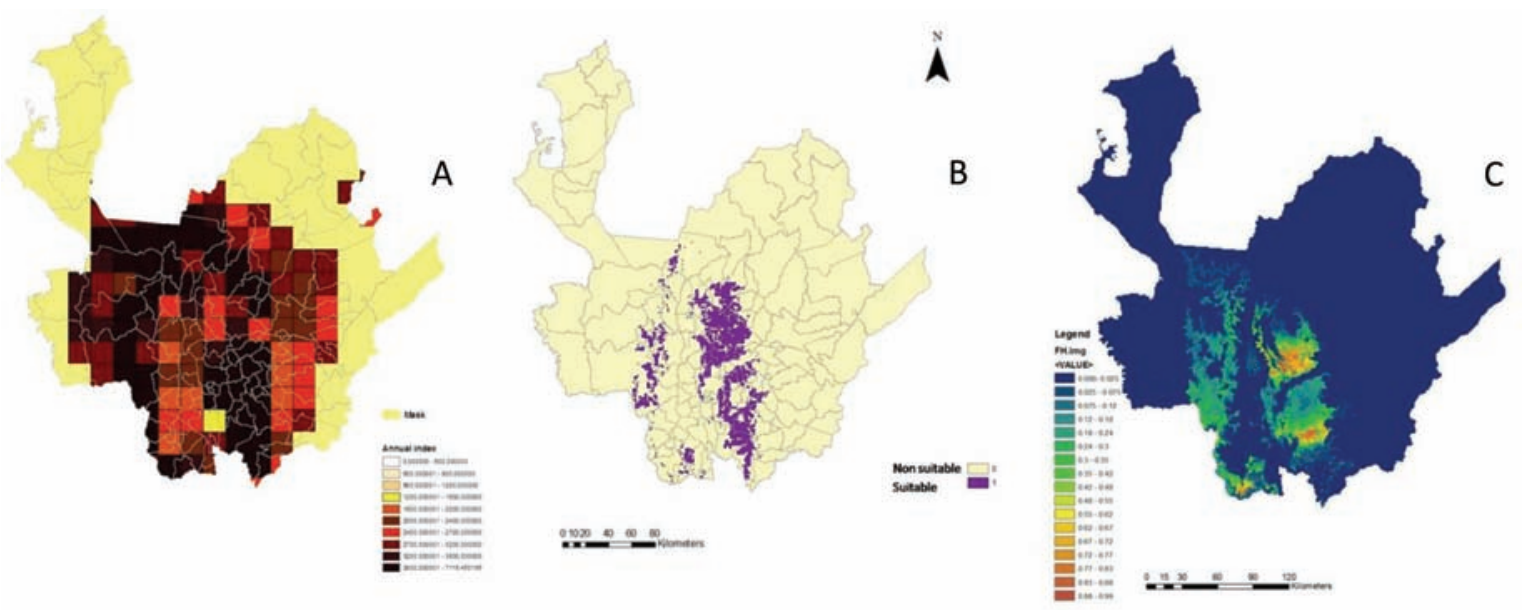

Fig. 6. (A) GDD-WB climate forecast risk index derived from the national scale climate GRID (18 x $18 \mathrm{~km})$ clipped to the boundary of Antioquia. Although much coarser in spatial resolution, the map generated by the climate grid forecast, when clipped to show only Antioquia, shows a compatible risk pattern when compared to the much higher resolution $\left(1 \mathrm{~km}^{2}\right) \mathrm{MaxEnt}_{\text {-BioClim }}$ model and GIS query-MODIS model for F. hepatica risk in Antioquia; (B) GIS-MODIS query model based on extrapolation of the range of values of elevation, EVI and LST day-night temperature difference values extracted from buffers centered on farm survey points; (C) MaxEnt ecological niche model for fascioliasis in Antioquia based on point location data from a 2008-2010 farm survey and BioClim environmental data variables. Warmer coloured areas have more suitable predicted conditions for F. hepatica.

ical value ranges were then used to extrapolate within the GIS to areas of Antioquia where no data were available (Fig. 6b). Results indicate that the predicted risk map pattern of the regional-scale GDD/WB climate grid forecast model $(18 \times 18 \mathrm{~km})$ was similar to the pattern of the higher resolution $\left(1 \mathrm{~km}^{2}\right)$ queryMODIS model.

\section{MaxEnt ecological niche model}

Using latitude-longitude coordinates of the selected 231 farm study sites and 19 Bioclim variables to represent climate features, an initial run of the MaxEnt software was used to select the nine BioClim variables ( $1 \mathrm{~km}^{2}$ resolution) that contributed most to the probability map model. A second run of the model using these nine variables was used to produce the probability surface shown in Fig. 6c. The risk pattern was again similar to patterns seen in the coarse resolution Climate Grid Forecast model. The receiver operator characteristic (ROC) graph output by the MaxEnt software revealed an area under the curve (AUC) value of 0.98 , and this indicates an excellent predictive model (Fig. 7). Area calculations based on the models indicated that the suitable area for fascioliasis in Antioquia represented 4,058 of the total $13,134 \mathrm{~km}^{2}$ $(30 \%)$ predicted as suitable in all of Colombia.

The MaxEnt-generated Jackknife statistics seen in Fig. 8 shows the individual BioClim variables that were most important to $F$. hepatica distribution models were annual mean temperature, mean temperature of the wettest quarter, annual precipitation and precipitation of the wettest quarter, i.e. Bio1, Bio8, Bio 12 and Bio 16, respectively. This result coincides with expected correlation of favourable temperatures $\left(>10^{\circ} \mathrm{C}\right.$ and $<25^{\circ} \mathrm{C}$, optimum $18^{\circ} \mathrm{C}$ ) and wet season moisture regime for progression of the snail-parasite system life cycle.

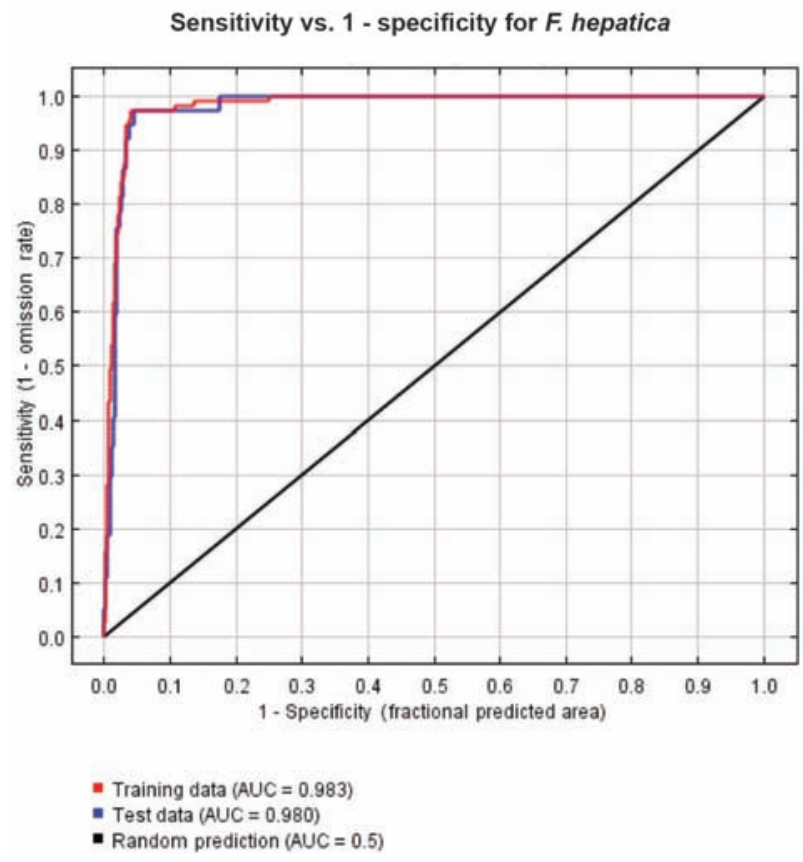

Fig. 7. MaxEnt receiver operator characteristic area under the curve (AUC) graph output. An AUC value of 0.98 indicates an excellent predictive model. 


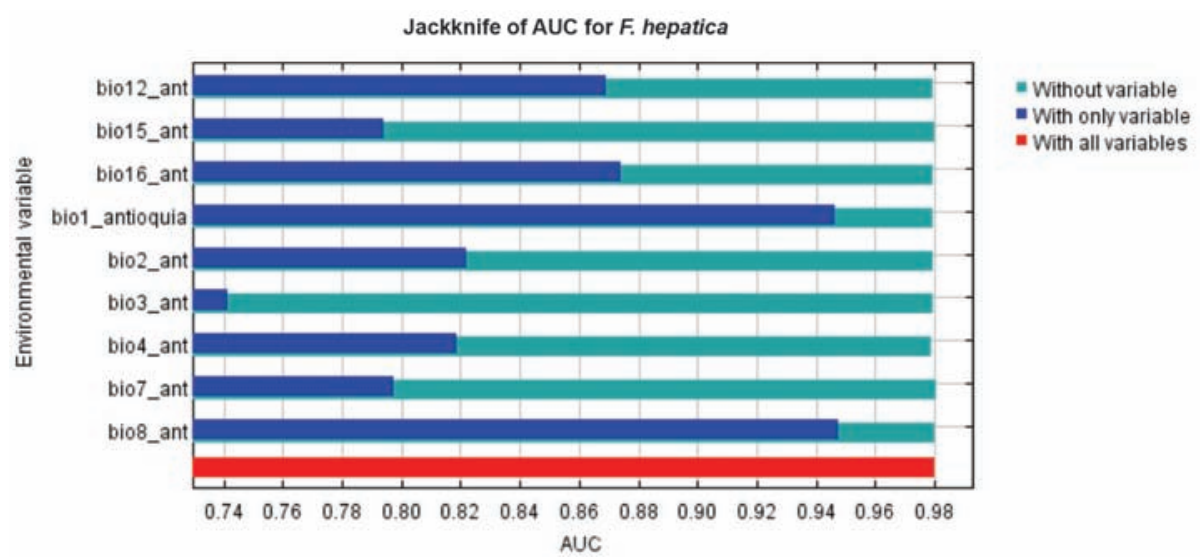

Fig. 8. Results of the jackknife test for the MaxEnt model for Antioquia showing the contribution of each of nine individual BioClim variables to the to the probability map model.

\section{Discussion}

GDD-WB forecast methods, previously developed for use in predicting climate-based $F$. hepatica risk elsewhere (Malone et al., 1987; Malone and Yilma, 1999; Fuentes, 2006, Dutra et al., 2010) were adapted for use under Colombian highlands conditions to map the endemic area and annual patterns of transmission using monthly climate grid $(18 \times 18 \mathrm{~km})$ data (Figs. 2 and 3). The GIS risk maps produced revealed that the predicted area of endemic fascioliasis risk is largely confined to the high altitude Andean region of Colombia (Figs. 2 and 3) where temperate climates compatible with the F. hepatica life cycle occur (i.e. wet hydrological regimes with extended periods of nearly saturated soils of neutral $\mathrm{pH}$ and $10-25^{\circ} \mathrm{C}$ temperature range (optimum $18{ }^{\circ} \mathrm{C}$ ). This result is corroborated by a prior national survey of $F$. hepatica and gastrointestinal nematodes in Colombia by Griffiths et al. (1986) who reported the absence of F. hepatica at elevations $<2,000 \mathrm{~m}$ above sea level.

\section{Seasonal transmission pattern}

Using daily climate records available from a representative meteorologic station in Antioquia, a Climate Based Parasite Forecast System software programme based on the GDD-WB concept was used to represent daily life cycle progression for 2007 and 2008 based on mean temperature and hydrological conditions that describe annual patterns of soil moisture content and surplus water (Fig. 5). Seasonal climate suitability patterns indicated that the major annual transmission occurs in cattle in the wet season (i.e. July-February) in Colombia.

The monthly and daily GDD-WB forecasts are "biology-based models", predicated on known biological requirements and thresholds available from the literature and can be driven by long-term-normal (e.g. 30 -year-average) or near-real-time monthly or daily climate station parameters. Seasonal transmission patterns were predicted by both monthly forecast values (Tables 4 and 5), and by the daily GDD-WB forecast

Table 5. Monthly Index1, water budget and GDD values, March 2008-February 2009.

\begin{tabular}{|c|c|c|c|c|}
\hline Month & Index 1 & Precipitation $(\mathrm{mm})$ & Water surplus (mm) & GDD \\
\hline March & 11 & 44.4 & 3.8 & 62 \\
\hline April & 38 & 150.1 & 14.1 & 64 \\
\hline May & 18 & 94.0 & 5.5 & 93 \\
\hline June & 17 & 1491 & 14.4 & 93 \\
\hline July & 41 & 145.8 & 14.5 & 93 \\
\hline August & 512 & 243.2 & 104.3 & 123 \\
\hline September & 663 & 306.8 & 190.1 & 94 \\
\hline October & 306 & 180.6 & 70.8 & 93 \\
\hline November & 232 & 165.8 & 55.3 & 93 \\
\hline December & 392 & 201.9 & 99.4 & 93 \\
\hline January & 363 & 207.0 & 89.7 & 93 \\
\hline February & 91 & 61.0 & 18.8 & 93 \\
\hline Total & 2684 & $1,949.6$ & 680.8 & 994 \\
\hline
\end{tabular}


Table 6. Critical values of considered environmental variables for the GIS query-MODIS model.

\begin{tabular}{lcc}
\hline \multirow{2}{*}{ Variable } & \multicolumn{2}{c}{ Range } \\
\hline Enhanced vegetation index* & 2008 & 2009 \\
Elevation $(\mathrm{m}$ above sea level) & $0.38-0.61$ & $0.36-0.57$ \\
$\mathrm{dT}^{* *}\left(\right.$ in $\left.^{\circ} \mathrm{C}\right)=$ LST $_{\text {day }}-$ LST $_{\text {night }}$ & $2097-2629$ & $2160-2789$ \\
\hline
\end{tabular}

*EVI index values range from 0 (indicating no vegetation) to 1 (indicating highly active photosynthesis)

$\because *$ Temperature difference.

graphical output (Fig. 5), but most accurately by the daily forecast. Daily forecast results indicated the optimum period for F. hepatica development and transmission in northern Antioquia began in July in 2007 vs. August in 2008. Results suggest there may be sufficient differences between years in intensity and seasonality of transmission that would justify distribution of annual fascioliasis forecasts to livestock producers and animal health workers.

\section{Annual variation in transmission}

The cumulative precipitation, soil moisture content, surplus water and annual forecast index values for March 2007-February 2008 were greater than the respective annual values for the March 2008-February 2009 period, suggesting that 2007-2008 was a higherrisk year (Tables 4 and 5; Fig. 5). According to Fuentes and Malone (1999), and Fuentes et al. (1999), index values below 600 indicate no risk, values between 601 and 1,500 show low risk, index values between 1,501 and 3,000 represent moderate risk and values above 3,000 indicate high risk. This is based on the requirement that $>600$ GDD under suitable soil moisture conditions (water storage within the top $50 \mathrm{~cm}$ ) is needed to complete one generation of the free-living and intramolluscan stages of $F$. hepatica. Taking into account the cumulative GDD values for each year, the forecast results show that a greater number of potential generations per year occurred in the 2007-2008 (3.94) than in 2008-2009 (3.31). These results are consistent with the well known annual climate driven variation in transmission intensity of $F$. hepatica in endemic areas (Ollerenshaw and Rowlands, 1959) and suggest national scale annual forecasts can be developed for Colombia by running the daily or monthly climate based forecast models using current data available from representative climate stations of the World Meteorological Organization (WMO) or divisional average climate data from the national climate service.

Results of the current study suggest the optimum time for a single annual herd treatment by adulticidal fluke drugs (e.g. albendazole, clorsulon) is in the early dry season in Colombia (2-3 months after the end of the major wet season fluke transmission period (i.e. April-May) when transmission is minimal and there has been time for the flukes to develop into bile duct stages most susceptible to adulticidal drugs. Treatment with drugs with high efficacy against immature and mature flukes (e.g. triclabendazole) might be given a month or two earlier.

Annual differences in the forecast were also evaluated to determine the influence of the El Niño/La NiñaSouthern Oscillation (ENSO) anomalies reported to occur at the time of the 2007-2009 study period (Table 7) (Climate Prediction Center Internet Team, 2011). In Antioquia, the period from March 2007 to February 2008 had higher forecast indices than the corresponding period of the following year and, therefore, had a higher predicted risk. A preliminary review of reports of ENSO anomalies, revealed that there were several La Niña episodes in this period, suggesting that ENSO phenomena may relate to a greater or lesser annual transmission of fascioliasis in Colombia.

Table 7. Cold and warm ENSO episodes by season in 2007 and 2008.

\begin{tabular}{|c|c|c|c|c|c|c|c|c|c|c|c|c|}
\hline \multirow{2}{*}{ Year } & \multicolumn{12}{|c|}{ Interval } \\
\hline & DJF & JFM & FMA & MAM & AMJ & MJJ & JJA & JAS & ASO & SON & OND & NDJ \\
\hline 2007 & 0.8 & 0.4 & 0.1 & -0.1 & -0.1 & -0.1 & -0.1 & -0.4 & -0.7 & -1.0 & -1.1 & -1.3 \\
\hline 2008 & -1.4 & -1.4 & -1.1 & -0.8 & -0.6 & -0.4 & -0.1 & 0.0 & 0.0 & 0.0 & -0.3 & -0.6 \\
\hline
\end{tabular}

The moving average temperatures start with December-February (DJF) and runs through November-January (NDJ). Warm episodes are shown in red and cold in blue, based on a threshold of $+/-0.5^{\circ} \mathrm{C}$ for the Oceanic Niño Index (ONI).

Source: Climate Prediction Center (http://www.cpc.ncep.noaa.gov/). Data from this meteorogical station , as well as the data used here, were obtained from EmpresasPúblicas de Medellín (EPM), located 6 ${ }^{\circ} 39^{\prime}$ North and $75^{\circ} 30^{\prime}$ West, IDEAM code number 2701523, Cucurucho, Santa Rosa de Osos municipality.

DJF = December, January, February; JFM = January, February, March; FMA = February, March, April; MAM = March, April, May; AMJ = April, May, June; MJJ = May, June, July; JJA = June, July, August; JAS = July, August, September; ASO = August, September, October; SON = September, October, November; OND = October, November, December; NDJ = November, December, January. 


\section{Municipality scale climate-based forecasts}

Although much coarser in spatial resolution, the map generated by the climate grid forecast $(18 \times 18$ $\mathrm{km}$ ), when clipped to show only Antioquia, shows a compatible risk pattern when compared to both the higher resolution $\left(1 \mathrm{~km}^{2}\right)$ MaxEnt-BioClim model and GIS query-MODIS model for mapping $F$. hepatica risk in Antioquia (Fig. 6).

These results suggest that climate-based prediction models may best be developed for use at two scales: (i) production of a national-scale climate grid forecast to map relative risk and seasonality of F. hepatica and (ii) production of $1 \mathrm{~km}^{2}$ scale risk maps that depict relative risk at higher resolution (municipality or department) using MaxEnt software with BioClim data parameters. Risk maps produced at either scale are based on long-term-normal climate parameters (30years for the national scale grid, 50-years for the MaxEnt-BioClim $1 \mathrm{~km}^{2}$ scale model) and thus represent distribution and abundance and average seasonal transmission patterns only. By contrast, the GIS queryMODIS model had the advantage, when compared to the MaxEnt-BioClim model, of using current MODIS climate surrogate data available via the Internet at 8-day (LST) and/or 16-day intervals (EVI) and thus could be developed in the future to issue current biweekly, monthly or annual forecasts of F. hepatica risk at municipality scales $\left(1 \mathrm{~km}^{2}\right)$. It is possible to obtain daily or monthly data for the current year covering all of Colombia at representative national or divisional climate stations (e.g. WMO meteorological stations) for use in national-scale current-year annual forecasts. Results of current year national forecasts, with the 1 $\mathrm{km}^{2}$ scale GIS query-MODIS models based on current year MODIS data, could be paired to produce current year risk maps. Taken together, results indicate it is possible to develop GIS decision-support systems for F. hepatica control programmes in Colombia and the Andes region at both a national and local scale.

\section{Conclusions}

(i) Climate forecasts based on GDD-WB analysis based on both monthly climate grid data (18 x 18 $\mathrm{km}$ ) and daily climate station data can be applied in Colombia when calculated by biology-based criteria and forecast methods reported in published models developed for use in other world regions (i.e. the USA, Ethiopia, southern Brazil).

(ii) Findings unique to current studies indicate that higher spatial resolution $F$. hepatica risk maps (1 $\mathrm{km}^{2}$ ) can be produced using prevalence data (231 farms in Antioquia) by two methods, (i) MaxEnt ecological niche modeling based on long-termnormal BioClim data; and (ii) GIS query and extrapolation of critical ranges of elevation and climate surrogate data from current MODIS environmental satellites (EVI and dT). The GIS queryMODIS method offers the possibility of high-resolution forecasting of inter-annual variation in climate-related risk of $F$. hepatica. High resolution models produced at $1 \mathrm{~km}^{2}$ scale by either method were comparable in geospatial pattern to national scale climate forecast grid $(18 \times 18 \mathrm{~km})$ data.

(iii) Pending further field epidemiology studies, results suggest that the optimum time for a single annual herd treatment by adulticidal fluke drugs is in the early dry season in Colombia when transmission is minimal and there has been time for flukes to develop to bile duct stages most susceptible to adulticidal drugs. Results also suggest that significant inter-annual variation may occur in intensity of transmission in Colombia, indicating the need for annual $F$. hepatica forecasts to alert the livestock industry of high risk climate years and high risk pasture conditions that may warrant additional annual treatment of herds during the wet season.

\section{Acknowledgements}

The authors thank Prixia Nieto, Paula Mischler and Jennifer C. McCarroll of the Geospatial Health laboratory at Louisiana State University for their GIS expertise and support and the Ministerio de Agricultura y Desarrollo Rural in Colombia for financing the project, MADR 200704629 680-900/2007. We gratefully acknowledge the broad support and hospitality of the many fine people in the farm communities and municipalities of Antioquia that made these studies possible.

\section{References}

Climate Prediction Center Internet Team, 2011. Cold and warm episodes by season. Available at: http://www.cpc.noaa.gov/ products/analysis_monitoring/ensostuff/ensoyears.shtml (accessed on January 2011).

Dennis WR, Stone WM, Swanson LE, 1954. A new laboratory and field diagnostic test for fluke ova in feces. J Am Vet Med Assoc 124, 47-50.

Dutra LH, Molento MB, Naumann CRC, Biondo AW, Fortes FS, Savio D, Malone JB, 2010. Mapping risk of bovine fasciolosis in the south of Brazil using geographic information systems. Vet Parasitol 169, 76-81. 
Fuentes MV, 2006. Remote sensing and climate data as a key for understanding fasciolosis transmission in the Andes, review and update of an ongoing interdisciplinary project. Geospat Health 1, 59-70.

Fuentes MV, Malone JB, 1999. Development of a forecast system for fasciolosis in Central Chile using remote sensing and climatic data in a geographic information system. Res Rev Parasitol 59, 129-134.

Fuentes MV, Valero MA, Bargues MD, Esteban JG, 1999. Analysis of climatic data and forecast indices for human fascioliasis at very high altitude. Ann Trop Med Parasitol 93, 835 850.

Griffiths IB, Parra DG, Vizcaino OG, Gallego MI, 1986. Prevalence of parasite eggs and cysts in faeces from dairy cows in Colombia. Trop Anim Health Prod 18, 155-157.

Malone JB, 2005. Biology-based mapping of vector-borne parasites by geographic information systems and remote sensing. Parassitologia 47, 29-52.

Malone JB, Williams TE, Muller RA, Geaghan JP, Loyacano AF, 1987. Fasciolosis in cattle in Louisiana, development of a system to predict disease risk climate, using the Thornthwaite water budget. Am J Vet Res 48, 1167-1170.

Malone JB, Yilma JM, 1999. Predicting outbreaks of fasciolosis: from Ollerenshaw to satellites. In: Fasciolosis, JP Dalton (ed.) Dublin City University, Republic of Ireland, 151-182 pp.

Marín A, Martínez CA, 1977. Incidencia e importancia econó- mica de la Distomatosis Hepática en Nariño. Revista Acovez 1, 32-34.

Mas-Coma S, Bargues MD, Valero MA, 2005. Fascioliasis and other plant-borne trematode zoonoses. Int J Parasitol 35, 1255-1278.

Mas-Coma S, Funatsu IR, Bargues, MD, 2001. Fasciola hepáti$c a$ and lymnaeid snails occurring at very high altitude in South America. Parasitology 123, 115-127.

Olaechea FV, 1994. Epidemiología y control de Fasciola hepatica en la Argentina. In: Enfermedades parasitarias de importancia económica en bovinos. Nari A, Fiel C (eds.). Ed. Hemisferio Sur, Buenos Aires, Argentina.

Ollerenshaw CB, Rowlands WT, 1959. A method for forecasting the incidence of fascioliasis in Anglesey. Vet Rec 71, 591598.

Pavlovsky EN, 1966. Natural nidality of transmissible diseases, with special reference to the landscape epidemiology of zooanthroponse. University of Illinois Press, Urbana, IL, USA.

Phillips SJ, Anderson RP, Schapire RE, 2006. Maximum entropy modeling of species geographic distributions. Ecol Model 190, 231-256.

Ruselle MP, Wilhelm WW, Olson RA, Power JF, 1984. Growth analysis based on degree days. Crop Science 24, 28-32.

Yilma JM, Malone JB, 1998. A geographic information system forecast model for strategic control of fasciolosis in Ethiopia. Vet Parasitol 78, 103-127. 